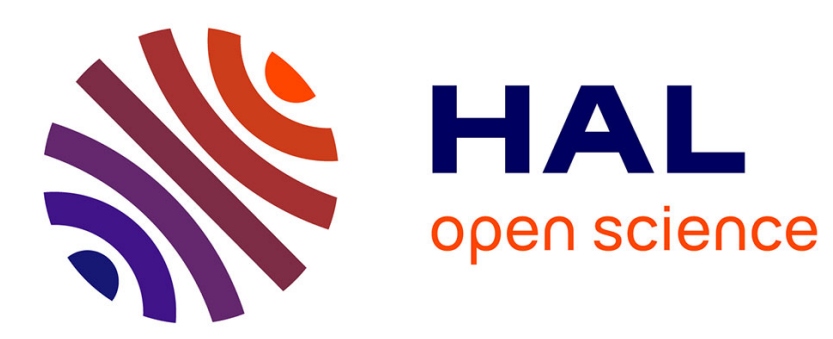

\title{
Flash temperature measurement during dry friction process at high sliding speed
}

\author{
Guy Sutter, Nicolas Ranc
}

\section{To cite this version:}

Guy Sutter, Nicolas Ranc. Flash temperature measurement during dry friction process at high sliding speed. Wear, 2010, 268 (11-12), pp.1237-1242. 10.1016/j.wear.2010.01.019 . hal-02269235

\section{HAL Id: hal-02269235 \\ https://hal.science/hal-02269235}

Submitted on 22 Aug 2019

HAL is a multi-disciplinary open access archive for the deposit and dissemination of scientific research documents, whether they are published or not. The documents may come from teaching and research institutions in France or abroad, or from public or private research centers.
L'archive ouverte pluridisciplinaire HAL, est destinée au dépôt et à la diffusion de documents scientifiques de niveau recherche, publiés ou non, émanant des établissements d'enseignement et de recherche français ou étrangers, des laboratoires publics ou privés. 


\title{
Flash temperature measurement during dry friction process at high sliding speed
}

\author{
G. Sutter ${ }^{\mathrm{a}, *}$, N. Ranc ${ }^{\mathrm{b}, \mathrm{c}}$ \\ a L.P.M.M., F.R.E. C.N.R.S. n 3236, I.S.G.M.P., Université Paul Verlaine - Metz, Ile du Saulcy, 57045 Metz Cedex 1, France \\ ${ }^{\mathrm{b}}$ Arts et Métiers ParisTech, L.M.S.P., U.M.R. C.N.R.S. n'8106, 151, boulevard de l'Hôpital, 75013 Paris, France \\ c Arts et Métiers ParisTech, P.I.M.M., 151, boulevard de l'Hôpital, 75013 Paris, France
}

Keywords:

Temperature measurement

Visible pyrometry

Flash temperatures

High speed friction

Dry friction

\begin{abstract}
A B S T R A C T
An experimental method is presented in this paper to measure flash temperatures of sliding surfaces. High sliding velocities are reached by using a ballistic set-up equipped with a high speed camera. The temperature field on the friction surface was recorded during the process. Tests were conducted under dry sliding conditions by using an identical material for the rubbing bodies, which are of middle hard steel (C22). Experiments showed that the temperature distribution generated by frictional heating is made up of small hot spots that correspond to the friction of asperities located on the sliding surface during very short time. Deduced from observations, maximum local surface temperatures can exceed about $1100{ }^{\circ} \mathrm{C}$ around an area less than $100 \mu \mathrm{m}$ in diameter.
\end{abstract}

\section{Introduction}

Present in most engineering applications, friction influences mechanical efficiency and plays a major role in the performance and life of the machine. The friction is an inevitable phenomenon which is a consequence of heating the rubbing parts (pieces in motion) at the interface and governs the action between the mobile part and fixed part. To optimize mechanical performance or just the life of one component, it is necessary to improve knowledge of the overheating, the mean or maximum values of temperature and the temperature distribution generated at the interface. Indeed, the existence of high-localized temperature (flash temperatures) at the surface can strongly influence the mechanical behavior of concerned materials. Kennedy [1] reports that such temperature can be responsible for oxide formation, spot weld, thermoelastic instabilities, thermomechanical failure, and wear. Similarly in manufacturing processes, the high local temperature at the tool-workpiece interface on the rake face or the clearance face determines the tool's life and the geometrical characteristics of the manufacturing part. For example, during the cutting process, the local temperature induced by friction under the tool tip accelerates the tool wear and generates residual stresses at the workpiece surface. The knowledge of the heating effects associated with friction is all the more significant when sliding velocity increases (due to the increase of the cutting speed) and when the

\footnotetext{
* Corresponding author. Tel.: +3303873153 67; fax: +330387315366

E-mail address: sutter@lpmm.univ-metz.fr (G. Sutter).
}

use of lubricant is reduced. Moreover, much of modeling of friction or wear mechanisms is based on the distribution of the surface temperature.

If it is well known that the temperature resulting from the frictional heating has very important consequences, it is also necessary to define an experimental measurement technique in order to measure the temperature field and to understand the mechanical and thermomechanical phenomena present during friction. The difficulty of the temperature measurement stands in the fact that the analyzed zone is difficult to probe without changing the friction conditions. In machining, the main method used for assessing temperature at the tool-chip interface is an embedded thermocouple [2-4]. Unfortunately, the introduction of the thermocouple in the cutting tool nearest to the interface alters the temperature distribution in the tool. In addition no direct measurement is obtained due to the distance between the thermocouple and the sliding surface. So it is possible to calculate only a mean temperature distribution at the tool-chip interface by using an analytical or numerical approach of the heat conduction problem. Moreover, only punctual measurements are possible and they have limited transient response due to their thermal inertia. With dynamic thermocouples [5], using just the difference of the temperature between the tool and the workpiece to generate electromotive force, only a mean temperature over the entire contact zone is obtained. For sliding surfaces, the thin film thermocouple (TFTC) used by Kennedy et al. [6] seems to be a good compromise to reduce disruption of the process and to have a high response time (in a range of $1 \mu \mathrm{s}$ ) and very small measuring junction. With a multi-junction sensor, Kennedy et al. observed temperature peaks (flash temperatures) which are much 


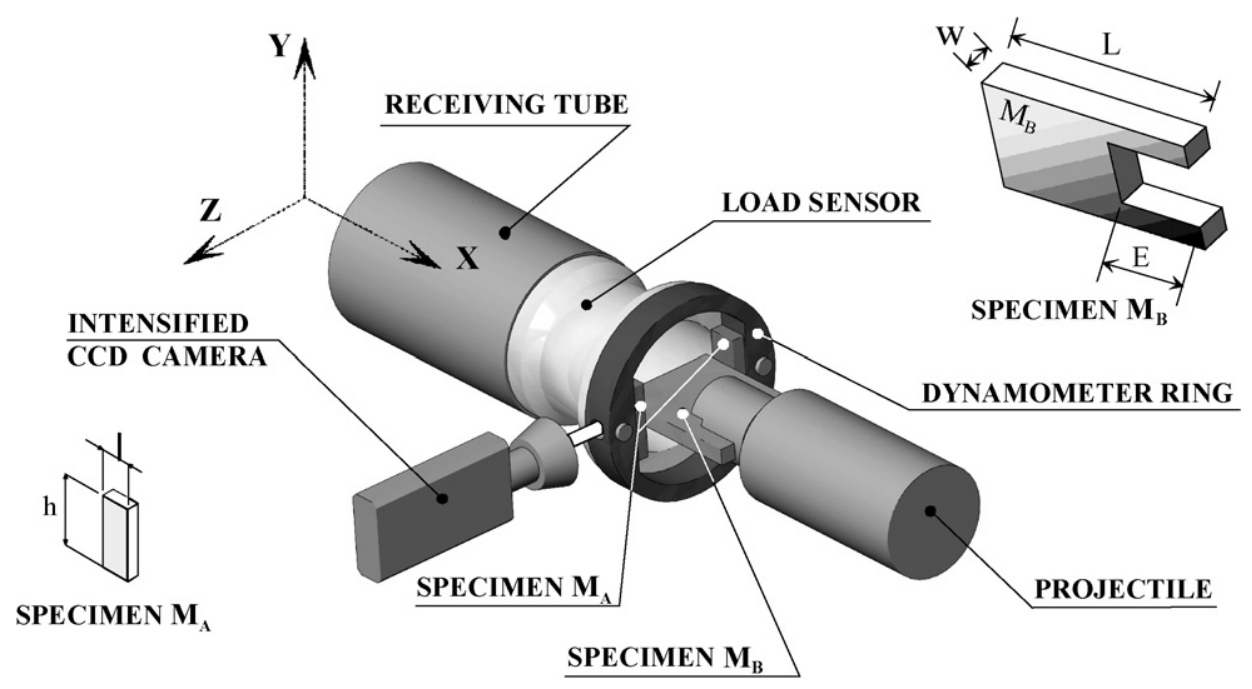

Fig. 1. Schematic of the experiment set-up used to measure heat during dry friction.

higher than the nominal value. Other numerous techniques have been developed to investigate temperature distribution of bodies in sliding contact. For example, during a manufacturing process, Wright et al. [7] proposed a metallographic method to determine temperature gradients in cutting tools on which the chip has been rubbing. Yeo and Ong [8] estimated thermal effect on the chip surface by a chip color approach. However, these two methods are laborious and difficult to use, particularly on surfaces which are scraped during the process. To provide information on the entire temperature distribution field and to identify the maximum temperature area, which can move with sliding conditions, the pyrometry technique $[9,10]$ seems to be actually the most adapted solution. This method has a very good spatial resolution and a short response time.

During the sliding motion, the friction energy is dissipated through a real area of contact which is generally different from the apparent area of contact. Depending on the manufacturing process, the surface roughness defines the profile of the contact surfaces. Although the surfaces are carefully prepared, they cannot be perfectly flat .The irregularities and asperities from surfaces that constitute the real area of contact can form interfacial junctions according to the compatibility of the sliding materials [11]. Plastic strains appear with the breaking of adhesive junctions and with the ploughing of hard asperities through the surface of the softer material. From these different surface and volumetric contributions that are generating energy during friction, it appears that the choices of the friction materials and surface roughness are very important.

It is usually assumed that the most important part of friction energy is consumed through plastic strain in the near-surface layers [12]. The microscopic observation of the different regions of a cross section of a worn surface shows that the largest plastic strain is located in a thickness of few microns from the sliding surface [13]. To obtain results in accordance with initial conditions, the structure of the material near the friction surface did not have to change by superimposing several stages of friction. Results obtained with several successive rub passes for steel sliding over copper show that the depth of the severe deformation increases with the subsequent passes. However with single pass tests [14] it was shown that the most important part of frictional energy $(>90 \%)$ is dissipated as plastic work within $5 \mu \mathrm{m}$ of contact surfaces and is transformed into heat. In addition, the real contact is formed by several confined areas (asperities) which can constitute thermo-junction. The increase of temperature of the bodies dur- ing friction is mainly initiated in the immediate vicinity of the real contact area and is extended by conduction to all material according to the time duration of the process. So the whole difficulty of temperature measurements lies in taking a picture of the initial temperature field in the near surface during a short duration (less than $1 \mathrm{~ms}$ ). Obtaining these experimental data is very important for a better understanding of thermal phenomena during friction.

The aim of this work is to propose an experimental approach to quantify the temperature fields generated at the interface of two contacting bodies in sliding contact, especially at high velocities. More precisely, the objective is to confirm and measure the magnitude of flash temperature in a sliding contact. However, if it is possible to estimate a mean value of the generated heat, a reliable measurement of temperature maps generally remains complex and difficult. In this study, in order to reach the contact zone, one of the sliding bodies is drilled. The temperature disturbance is limited by the use of a radiation technique. In addition, direct access to the friction zone allows to avoid interpolation calculations. A ballistic device is used in order to generate dry friction and produce a large range of sliding velocities [15]. In this paper, the interpretation of temperature fields is realized at $35 \mathrm{~m} / \mathrm{s}$. To reduce the parameters which can interfere with the results, the rubbing surfaces are precision ground, with the same material, a middle hard steel C22, used for each of the two parts. Only one pass is realized by a specimen to obtain a continuously fresh rubbing surface.

\section{Experimental device}

\subsection{High speed friction device}

To reach high sliding velocities, a dynamic set-up used was developed to study processes of interaction during cutting under severe conditions [16]. An air gun is used to propel a projectile inside a launch tube designed to avoid any rotation. This tube, which is connected to an air gun, precisely drives the projectile and is long enough to assure a constant velocity after the launching. The velocity range can vary from 10 to $100 \mathrm{~m} / \mathrm{s}$ according to the gun pressure. The mass of the projectile is chosen in order to have a kinetic energy larger than the mechanical work consumed during the friction process. The sliding velocity is thus nearly constant during the process and quasi-stationary conditions are realized. A second tube coaxial to the first one receives the projectile with a gradual slowing down after the test. The friction process, as shown in Fig. 1, is taking place at the entry of the receiving tube. Contrary 
Table 1

Chemical composition, main mechanical and thermal properties of the medium-low carbon steel C22.

\begin{tabular}{|c|c|c|c|c|c|}
\hline Mechanical properties & Hardness (Brinell) & Yield stress (MPa) & Ultimate tensile strength ( $\mathrm{MPa})$ & Specific heat capacity $(\mathrm{J} / \mathrm{kg} \mathrm{K})$ & Thermal conductivity $(\mathrm{W} / \mathrm{m} \mathrm{K})$ \\
\hline $\mathrm{C} 22$ & 120 & 340 & 405 & $\approx 480$ & $\approx 52$ \\
\hline Elements $\times 10^{-3} \mathrm{wt} \%$ & \multicolumn{2}{|c|}{ C } & Mn & $\mathrm{S}$ & $\mathrm{P}$ \\
\hline $\mathrm{C} 22$ & \multicolumn{2}{|c|}{$140-200$} & $300-600$ & $\max 5$ & $\max 4$ \\
\hline
\end{tabular}

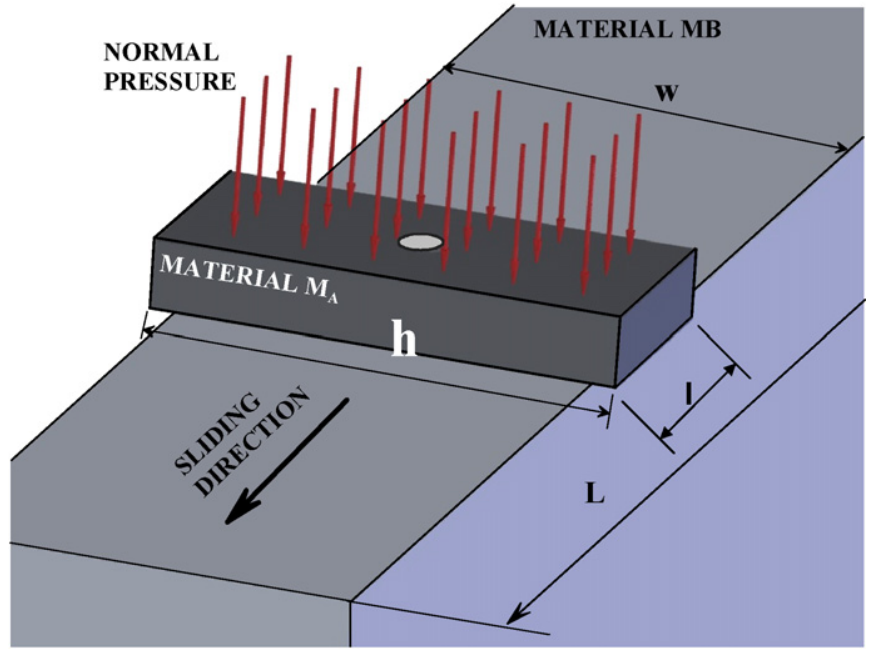

Fig. 2. Geometric characteristics of friction generated on the present experimental set-up.

to the earlier cutting study [16], the specimen is not fixed on the projectile but held in position before impact.

A dynamometer ring, which ensures the compressive force during the friction, is fixed on a load sensor made up of a thin tube and strain gages. Two rectangular specimens $M_{\mathrm{A}}(h=24 \mathrm{~mm} \times \ell=$ $12 \mathrm{~mm}, e=5 \mathrm{~mm}$ ) are symmetrically fixed inside this dynamometer ring. During the friction process, the projectile launched by the air gun impacts the specimen $M_{\mathrm{B}}(W=10 \mathrm{~mm} \times L=60 \mathrm{~mm}$, $E=10 \mathrm{~mm}$ ). The sliding movement is realized after the impact of the projectile on the specimen $M_{\mathrm{B}}$. Dry friction of medium-low carbon steel, for which the chemical composition and the main mechanical characteristics are indicated in Table 1 , is studied in this work. The surfaces are obtained by grinding operation following the sliding direction and the surface roughness is $R_{\mathrm{a}}=0.8 \mu \mathrm{m}$. All the specimens are machined together to admit that the geometrical defects are negligible. To distinguish various parts of the device, the specimen $M_{\mathrm{A}}$ will indicate the fixed specimen and $M_{\mathrm{B}}$ the mobile specimen.

\subsection{Temperature field measurement on the sliding surface}

The experimental technique used to measure the temperature during the sliding process is based on the visible pyrometry technique developed previously for the measurement of the temperature during the cutting process $[17,18]$. The pyrometry technique is non intrusive and in order to have a weak sensitivity of the emissivity of the surface on the determination of the temperature, the visible pyrometry technique is used. This measurement is carried out with an intensified CCD Camera whose spectral range is between $0.4 \mu \mathrm{m}$ and $0.8 \mu \mathrm{m}$. The aperture time of the camera can be $40 \mu \mathrm{s}, 300 \mu \mathrm{s}$ and $500 \mu \mathrm{s}$. An objective with a focal length of $80 \mathrm{~mm}$ allows to obtain a spatial resolution of $4 \mu \mathrm{m}$.

To reach the zone of friction, a hole is drilled through the ring and through the fixed specimen. The diameter of the hole is $2 \mathrm{~mm}$ and remains small compared to the size of the specimen (Fig. 2).
Table 2

Experimental conditions for the different tests.

\begin{tabular}{llllc}
\hline Test reference & $\begin{array}{l}\text { Sliding velocity } \\
(\mathrm{m} / \mathrm{s})\end{array}$ & $\begin{array}{l}\text { Normal } \\
\text { pressure }(\mathrm{MPa})\end{array}$ & Delay $(\mu \mathrm{s})$ & $\begin{array}{l}\text { Aperture time } \\
(\mu \mathrm{s})\end{array}$ \\
\hline 1 & 33.4 & 90.7 & 101 & 40 \\
2 & 35.8 & 91.2 & 463 & 40 \\
3 & 33.9 & 89.3 & 593 & 40 \\
4 & 34.2 & 88.4 & 640 & 40 \\
5 & 34.5 & 84.9 & 325 & 300 \\
6 & 34.2 & 84.9 & 381 & 300 \\
7 & 33.8. & 84 & 573 & 300 \\
8 & 33.4 & 92.8 & 261 & 500 \\
\hline
\end{tabular}

The temperature measurement device is calibrated on a black body (Pyrox: PY24, temperature range: $400-1600^{\circ} \mathrm{C}$, temperature uncertainty: $1^{\circ} \mathrm{C}$ ). For example, the curves in Fig. 3 show the evolution of camera level according to the black body temperature for the aperture times of $40 \mu \mathrm{s}$ and $300 \mu \mathrm{s}$.

\section{Results and discussion}

A series of tests was carried out for aperture time of the camera of $40 \mu \mathrm{s}, 300 \mu \mathrm{s}$ and $500 \mu \mathrm{s}$. Table 2 sums up the different experimental conditions (each test is reproduced twice to confirm the recording and the mean values are notified). The delay is the time between the beginning of friction and the beginning of the aperture of the camera. For a sliding speed of $34 \mathrm{~m} / \mathrm{s}$, the length of the specimen corresponds to a friction duration of about $1700 \mu \mathrm{s}$. Fig. 4 represents the evolution of the tangential force according to time for the test 3 . The average value of this force during friction is calculated by the usual relation $F_{\mathrm{T}}=1 /\left(t_{f}-t_{i}\right) \cdot \int_{t_{i}}^{t_{f}} f_{\mathrm{T}} \mathrm{d} t$ where $f_{\mathrm{T}}$ is the instantaneous tangential force, $t_{f}$ and $t_{i}$ respectively are the initial and the final friction time corresponding to a constant normal stress. Indeed, as shown in Fig. 1, the specimen $M_{\mathrm{B}}$ has a specific design to assure its guiding through the receiving tube after the impact [15]. This design imposes a variation in rigidity, which results in a decreasing normal stress (see Fig. 4) after a sliding distance $(L-E-\ell)$. In the case of test 3 , a constant normal loading is considered for a distance of $38 \mathrm{~mm}$ which corresponds to an average tangential force equal to $1.35 \mathrm{kN}$. In Fig. 4, the delay and the aperture time of the camera are specified. It must be noted, that the low frequency oscillations observed on the recorded signal, are produced by the eigenmode of the sensor and are filtered by considering the average value of this signal. The moving time in the hole of a material point on the mobile specimen is approximately $70 \mu \mathrm{s}$. Normal pressure is deduced from the dimensions of samples measured at the beginning of each test and the stiffness of the dynamometer ring.

Two thermographs which correspond to the tests 3 and 5 are represented respectively in Figs. 5 and 6. These two thermographs are representative of all thermographs obtained during these tests. The temperatures are calculated by using the respective calibration curves given in Fig. 3. Thus, this temperature determination method implies that those temperatures remain constant during the aperture time of the camera. This assumption will be justified later in this document. $X$ and $Y$ axes, with origins in the center of the hole, are directed respectively along the sliding direction and orthogonal to the sliding direction. 

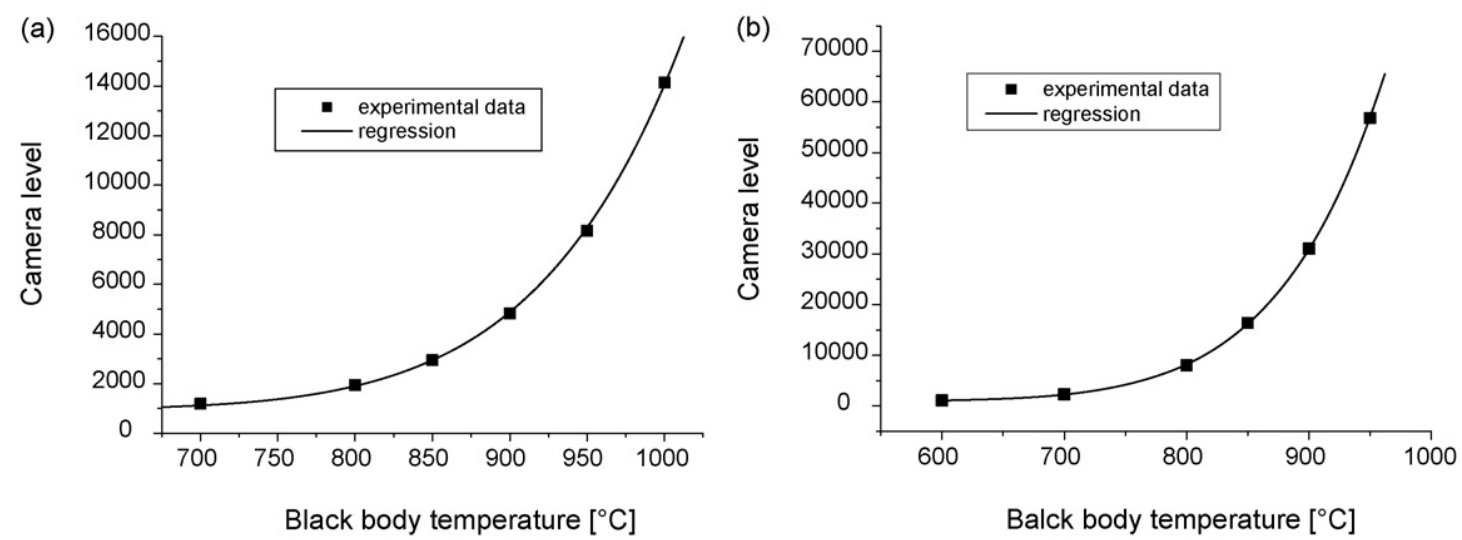

Fig. 3. Calibration curve of the intensified CCD camera. (a) Aperture time of $40 \mu \mathrm{s}$ (b) Aperture time of $300 \mu s$.

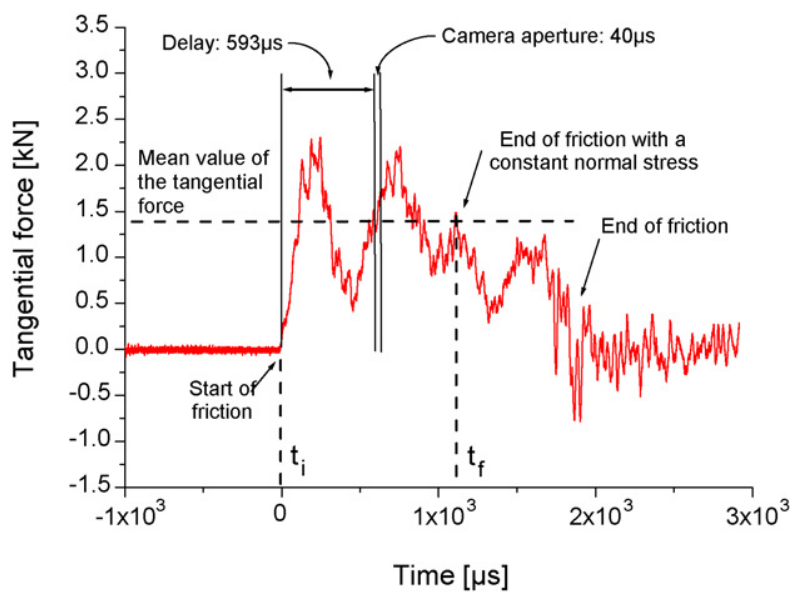

Fig. 4. Recorded signal by the load sensor according to time during test 3.

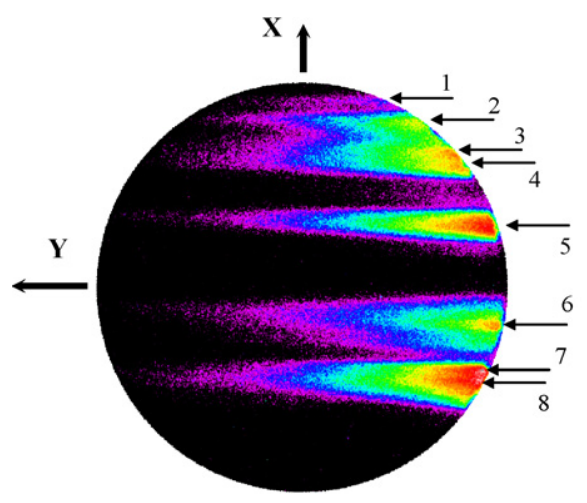

Temperature in ${ }^{\circ} \mathrm{C}$

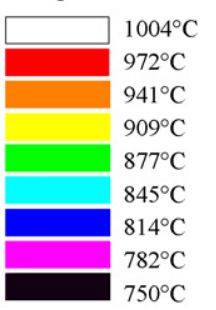

Fig. 5. Thermography of the sliding surface for a sliding velocity of $33.9 \mathrm{~m} / \mathrm{s}$ and a $40 \mu \mathrm{s}$ aperture time of the camera (test 3 ).

Table 3

Location and value of the different hot spots.

\begin{tabular}{lccccc}
\hline Streak reference & \multicolumn{2}{c}{ Maximal temperature $\left({ }^{\circ} \mathrm{C}\right)$} & \multicolumn{2}{c}{ Position along $X$ axis $(\mathrm{mm})$} \\
\cline { 2 - 3 } \cline { 5 - 6 } & Test 3 & Test 5 & & Test 3 & Test 5 \\
\hline 1 & 839 & 848 & & 1.08 & 0.95 \\
2 & 917 & 918 & & 0.97 & 0.85 \\
3 & 942 & 901 & & 0.70 & 0.76 \\
4 & 951 & 852 & & 0.76 & 0.54 \\
5 & 991 & 780 & & 0.35 & 0.40 \\
6 & 952 & 781 & & -0.25 & 0.07 \\
7 & 1004 & 861 & & -0.49 & -0.14 \\
8 & 998 & 901 & -0.54 & -0.26 \\
9 & & 838 & & -0.46 \\
\hline
\end{tabular}

These two thermographs are similar in spite of a very different aperture time. They both present a certain number of hot spots emerging from the right-hand side of the hole in the mobile specimen and forming streaks towards the left of the hole with a decreasing temperature. During tests 3 and 5, respectively eight and nine streaks can be counted. The maximum temperatures vary between $839^{\circ} \mathrm{C}$ and $1004^{\circ} \mathrm{C}$ for test 3 and between $780^{\circ} \mathrm{C}$ and $918^{\circ} \mathrm{C}$ for test 5 ; Table 3 gives the maximum temperatures measured and their location along $X$ axis. Thermographs, presented in Figs. 5 and 6, highlight the same temperature levels even though measured with very different aperture times and thus show that during $300 \mu$ s the temperature seems to be stationary.

Fig. 7a presents the temperature profile along the axis $X$ around the hot spot 5 (test 3) where the maximum temperature is $991^{\circ} \mathrm{C}$. The origin of distances in Fig. 7a is centered on the hot spots in order to make the reading easier. Due to the difficulty to define the hot zone width, this size will be chosen in an arbitrary way like the width corresponding to a temperature higher than $90 \%$ of the maximum temperature. This choice is a compromise between sufficiently weak variation in temperature in the hot source $(10 \%$ of the maximum temperature in our case) and enough variation compared to the thermal sensitivity of our measurement device. With this definition, the width of the hot spot (5) is estimated to be $130 \mu \mathrm{m}$, corresponding to a temperature higher than $864^{\circ} \mathrm{C}$. Fig. $7 \mathrm{~b}$ gives the temperature evolution along the $Y$ axis for the hot spots (5), (7) and (2). The origin of the distances of each hot spot in this figure is placed on the edge of the hole and directed along the $Y$ axis. A temporal scale obtained by dividing the distance from the edge of the hole by the sliding velocity, is plotted at the top of the



Fig. 6. Thermography of the sliding surface for a sliding velocity of $34.5 \mathrm{~m} / \mathrm{s}$ and a $300 \mu$ s aperture time of the camera (test 5). 

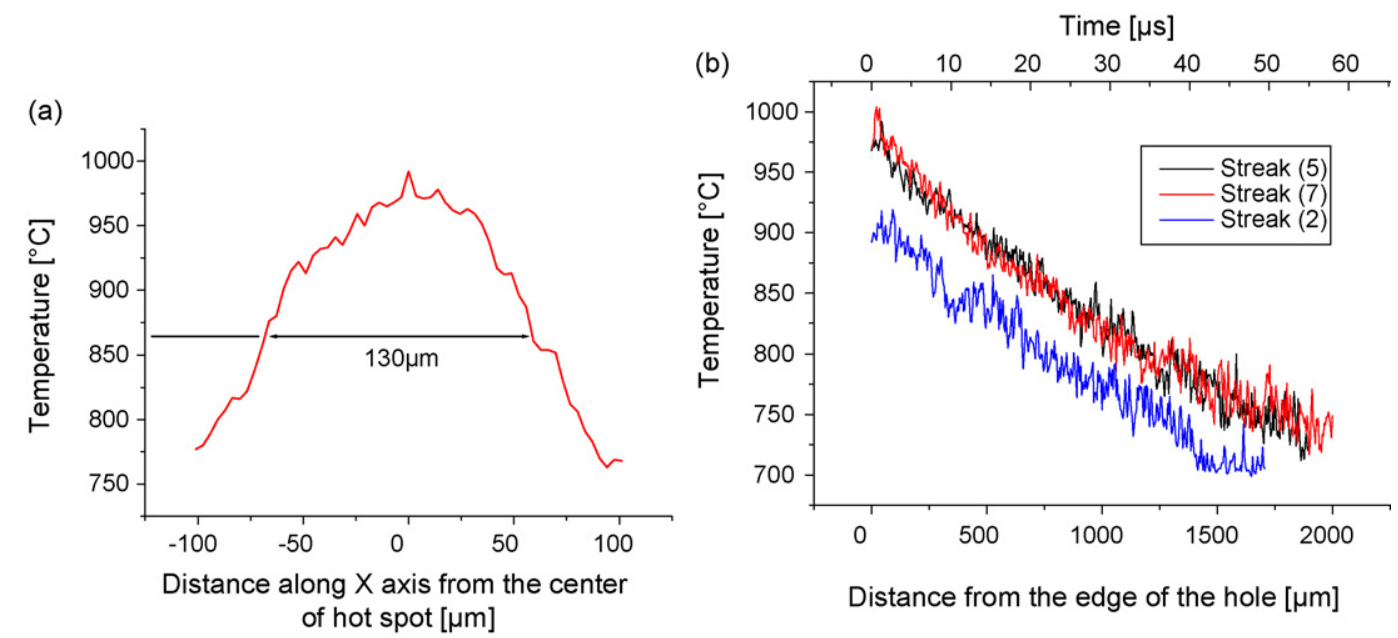


point (2).

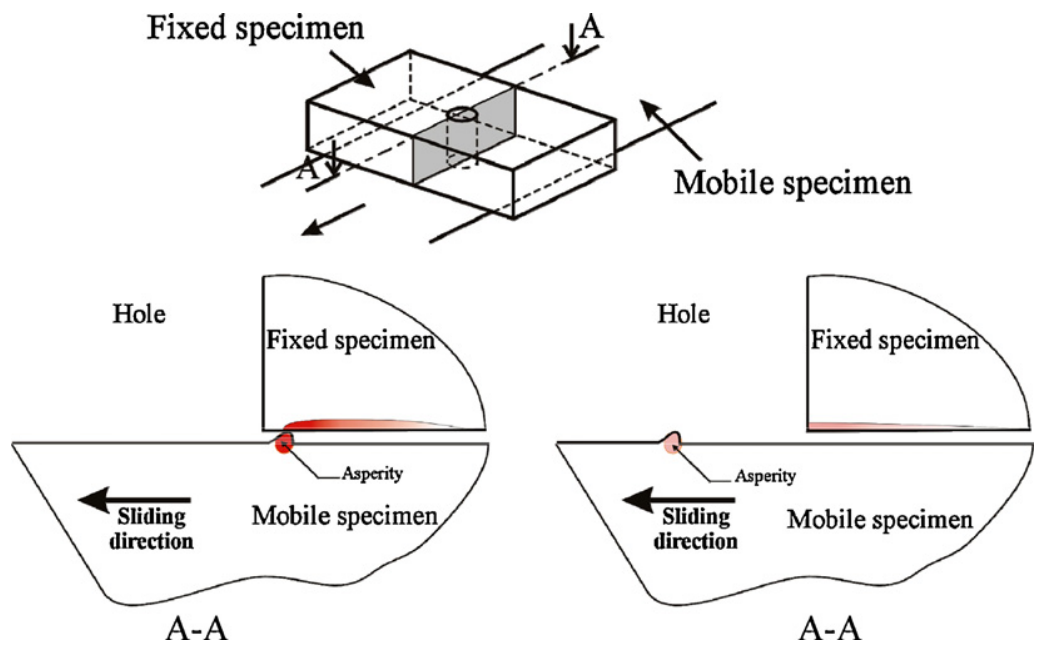

Fig. 8. Thermal effect associated with an asperity located on the mobile specimen on plane A-A.

graph to ensure a better comparison of results. For the hot spots 7 and 5 (test 3), whose temperatures at the friction zone exit are almost identical, a very good reproducibility of the temperature evolution can be noticed. For the hot point (5), the temperature decreases from $1000^{\circ} \mathrm{C}$ to $800^{\circ} \mathrm{C}$ in approximately $25 \mu \mathrm{s}$ whereas for hot point (2) the time to decrease from $900^{\circ} \mathrm{C}$ to $700^{\circ} \mathrm{C}$ is slightly longer (approximately $30 \mu \mathrm{s}$ ). Due to the similar rubbing surfaces (same roughness, same materials) used during the tests, it can be supposed that the asperities located on the specimens $M_{\mathrm{A}}$ and $M_{\mathrm{B}}$ are submitted to the same heating and also generate the same temperatures.

Two mechanisms could explain these temperature results. In the first one, an asperity which is located on the mobile specimen is considered. Before emerging in the hole, it warms up during friction with the fixed specimen (configuration schematized in Fig. 8). The camera observes this hot asperity, which emerges from the right of the hole and which moves along the $Y$ axis with a decreasing temperature due to the conduction through the mobile specimen and to the convection with the air located in the hole. The passage time of the asperity in the hole is approximately $60 \mu \mathrm{s}$. According to the triggering of the camera which occurred during the friction process, hot streaks which are in the middle of the hole and not only on the edge could have been observed. However, this type of streak is not observed in our experimental results.
In the second possible mechanism, an asperity which is now located on the fixed specimen, warms up by friction. This hot asperity will also heat the mobile specimen by contact (as shown in Fig. 9). On this part, as a function of the number of asperities in contact, hot streaks are initiated from the contact points. The temperature of these streaks decreases along the $Y$ axis because of the heat transfer phenomena. In this case, the camera also records hot



A-A

Fig. 9. Thermal effect of an asperity supposed located on the fixed specimen in the plane A-A. 
Table 4

Estimation of the distance between the asperities and the edge of the hole for the test 3 .

\begin{tabular}{ll}
\hline Streak reference & $\begin{array}{l}\text { Distance } \\
\text { Asperity-edge of the hole }(\mathrm{mm})\end{array}$ \\
\hline 1 & 0.83 \\
2 & 0.35 \\
3 & 0.21 \\
4 & 0.16 \\
5 & 0 \\
6 & 0.16 \\
7 & 0 \\
8 & 0 \\
\hline
\end{tabular}

streaks where temperatures are stationary during this time. Moreover streaks always seem to emerge from the right-hand side of the hole and the maximum temperature primarily depends on the distance between the edge of the hole and the location of the asperity on the fixed specimen. Constant temperatures were observed throughout all the aperture times of the camera ( $40 \mu \mathrm{s}$ or $300 \mu \mathrm{s})$; this allows to conclude that this parameter has a negligible effect on the temperature measurement.

In accordance with thermographic observations and previous analysis, this second mechanism seems to correspond to the effective process.

According to these conclusions the position of the asperity on the fixed specimen can be determined from the maximum temperature of one streak (at the edge of the hole) and from the temperature decrease of the streak (7) given in Fig. 7b. In the case of test 3 , it is supposed that the streak no. 7 , which corresponds to the maximum temperature, is located very close to the edge. In Table 4, the estimations of the distances between the asperities and the edge of the hole are reported for each streak. The minimal measurable temperature being above $650^{\circ} \mathrm{C}$, beyond a distance of approximately $2 \mathrm{~mm}$, the thermal effects associated with an asperity are also not visible in the hole.

\section{Conclusions}

This experimental investigation has been carried out in order to understand mechanism of the heat generation during the friction. The temperature field at the interface of sliding surfaces is measured by visible pyrometry using an intensified CCD camera. Tests are conducted under dry sliding conditions with contacting bodies made from medium-low carbon steel and for a sliding velocity of $34 \mathrm{~m} / \mathrm{s}$. The originality of this device lies in the fact that no transparent materials are necessary to reach the contact surface. The temperature recorded during the process confirms the non-uniformity of the contact temperature field and shows the existence of very small hot spots. Deduced from the experimental process, the flash temperature can exceed $1100^{\circ} \mathrm{C}$ over an area of about $100 \mu \mathrm{m}$ in diameter. These high-localized temperatures resulted from contact between very small asperities localized on the mobile specimen and the stationary slider.

Due to the fact that similar maximum temperature are reached during the tests at the same sliding velocity, the shape and the spacing between the contacts seem to have limited effect at high sliding velocities. For similar surface roughness, main parameters governing the temperature magnitude remain speed, normal pressure and thermal properties of the contacting materials. The performances of this equipment allow at the moment to consider a more systematic study of these various parameters.

\section{References}

[1] F.E. Kennedy, Thermal and thermomechanical effects in dry sliding, Wear 100 (1984) 453-476.

[2] T.I. EL-Wardany, E. Mohamed, M.A. Elbestawi, Cutting temperature of ceramic tools in high speed machining of difficult-to-cut materials, Int. J. Mach. Tools Manuf. 36 (1996) 611-634.

[3] D.A. Stephenson, Tool-work thermocouple temperature measurementstheory and implementation issues, Trans. ASME J. Eng. Ind. 115 (1993) 432437.

[4] T. Kitagawa, A. Kubo, K. Maekawa, Temperature and wear cutting tools in highspeed machining of Inconel 718 and Ti-6Al-6V-2Sn, Wear 202 (1997) 142 148.

[5] M.C. Shaw, Metal Cutting Principles, Oxford University Press, 1984.

[6] F.E. Kennedy, D. Frusescu, J. Li, Thin film thermocouple arrays for sliding surface temperature measurement, Wear 207 (1997) 46-54.

[7] P.K. Wright, E.M. Trent, Metallographic methods of determining temperature gradients in cutting tools, J. Iron Steel Inst. (1973) 364-368.

[8] S.H. Yeo, S.H. Ong, Assessment of the thermal effect on chip surfaces, J. Mater. Process. Technol. 98 (2000) 317-321.

[9] G. Boothroyd, Temperatures in orthogonal metal cutting, Proc. Inst. Mech. Eng. 177 (1963) 789-802.

[10] R.C. Dewes, E. Ng, K.S. Chua, P.G. Newton, D.K. Aspinwall, Temperature measurement when high speed machining hardened mould/die steel, J. Mater. Process. Technol. 92-93 (1999) 293-301.

[11] E. Rabinowicz, The determination of the compatibility of metals through static friction tests, ASLE Trans. 14 (1971) 198-205.

[12] D.A. Rigney, J.P. Hirth, Plastic deformation and sliding friction of metals, Wear 53 (1979) 345-370.

[13] J.H. Dautzenberg, J.H. Zaat, Quantitative determination of deformation by sliding wear, Wear 23 (1973) 9-19.

[14] F.E. Kennedy, Single pass rub phenomena-analysis and experiment, J. Lubr. Technol. 104 (1982) 582-588.

[15] G. Sutter, S. Philippon, A. Molinari, An experimental investigation of dry friction for a large range of sliding velocities, Matériaux et Techniques HS (2004) 33-37.

[16] G. Sutter, Chip geometries during high speed machining for orthogonal cutting conditions, Int. J. Mach. Tools Manuf. 45 (2005) 719-726.

[17] G. Sutter, N. Ranc, Temperature fields in a chip during high speed orthogona cutting - an experimental investigation, Int. J. Mach. Tools Manuf. 47 (2007) 1507-1517.

[18] N. Ranc, V. Pina, G. Sutter, S. Philippon, Temperature measurement by visible pyrometry-orthogonal cutting application, J. Heat Transfer ASME 126 (2004) 931-936. 